\title{
Selecting a Doctoral Dissertation Supervisor: Analytical Hierarchy Approach to the Multiple Criteria Problem
}

\author{
Subhajyoti Ray \\ Xavier Institute of Management, Bhubaneswar \\ Orissa, India
}

subhajyoti@ximb.ac.in

\begin{abstract}
Perhaps the most significant decision a doctoral student makes in the beginning of her research career is the selection of a thesis supervisor. Most often these decisions are in the form of a selection problem from a finite number of choices. The selection is based on a set of criteria, such as professors' reputation, knowledge, and matching of interests among others. However, the application of these criteria in selecting a supervisor is often done in an unplanned manner, which can become one of the reasons for regret, lack of motivation, and poor quality of research output. The need for having a supervisor who fits well with the students' preferences can hardly be overemphasized. This requires that students should select their supervisor in an objective manner, taking all factors and their own priorities into account. In order to address this need of doctoral students, the paper aims to demonstrate the use of analytical hierarchy process (AHP) in the selection of a thesis supervisor. A survey of doctoral students is conducted to obtain a list of criteria that are significant for selection of a research guide and then modeled as an AHP problem. A survey of junior and senior doctoral students is also conducted to ascertain the relative weights of the criteria elements to demonstrate the application of the proposed method.
\end{abstract}

Keywords: Thesis supervisor, doctoral dissertation, analytical hierarchy process, doctoral students, multiple criteria

\section{Introduction}

A fundamental characteristic of doctoral research is that it is carried out under the guidance of one or more academic supervisors. Although researchers have paid attention to many aspects of student learning and research in management education, one facet still seriously overlooked is that of research supervision (Armstrong, Allison, \&Hayes, 2004). Several problems, such as poor completion rates of research degrees (Burnett, 1999) and delayed completion of thesis (Garcia,

Material published as part of this publication, either on-line or in print, is copyrighted by the Informing Science Institute. Permission to make digital or paper copy of part or all of these works for personal or classroom use is granted without fee provided that the copies are not made or distributed for profit or commercial advantage AND that copies 1) bear this notice in full and 2) give the full citation on the first page. It is permissible to abstract these works so long as credit is given. To copy in all other cases or to republish or to post on a server or to redistribute to lists requires specific permission and payment of a fee. Contact Publisher@InformingScience.org to request redistribution permission.
Malot, \& Brethower, 1988), have been found in work related to thesis in postgraduate and higher levels of education. For example, Rudd (1985) found that in UK $40 \%$ to $50 \%$ of post graduate students failed to complete their dissertation in social sciences. The quality of supervision has been often indicated as the main reason for these problems (Dillon \& Malott, 1981; Zoia, 1981). Students have expressed dissatisfaction 
with the process of supervision (Hockey, 1991) with reasons for dissatisfaction, which include poor direction and structure (Acker, Hill, \& Black, 1991), allocation to a supervisor with interests not matching with those of the student, and insufficient guidance and time scaling (Eggleston \& Delamont, 1983; Wright and Lodwick, 1989). Such dissatisfaction rates have been found to be higher in the domain of social sciences than in natural sciences (Young, Fogarty \& McRea, 1987).

In a study of the research supervision process for postgraduate students, Eggleston and Delamont (1983), found that the matching of student to supervisor for effective relationships is crucially important. The question that arises is how can this match between student and supervisor be made? In a doctoral level program, the student chooses a supervisor and has to develop a relationship with this individual.

This relationship is different in many ways from the relationships that students have had with the lecturers who delivered most of the courses. For example, research students do need guidance, but they also need to develop sufficient autonomy and freedom to design and execute their own projects (Cornwall, Schmithals, \& Jaques, 1977; Harding, 1973). Clearly, there are several qualities that a student expects to see in her research supervisor, all of which may or may not be of equal significance to the student. Consequently, the process of selection of the supervisor becomes one of the critical factors in determining the degree of fit between the student and her supervisor.

Ideally a student should know the key attributes she wishes to see in her supervisor and their relative importance, and then be able to choose the supervisor who best fits her priorities. There are no studies that have looked into the method of supervisor selection, and this is where this study hopes to fill the gap. This study proposes and demonstrates the application of a multiple criteria based selection method viz Analytical Hierarchy Process (AHP) for research supervisor selection.

The next section discusses the details of the methodology used in this paper.

\section{Methodology}

This study was conducted in two phases. The first phase may be described as the formulation phase where the basic selection problem was formulated as a multi criteria decision making problem. The second phase was the demonstration phase where the formulated problem was actually applied on a set of participants in the study to come out with conclusions for the larger audience of future research students.

In the first phase of the study doctoral students at the authors' institute were asked to list all factors they would consider or would recommend one should consider before selecting a thesis supervisor. The simple question that was asked is, "What are important characteristics that you look for in a faculty member before selecting her or him as a thesis supervisor?" There were 47 students in the Ph.D. programme during the time of study, of which 23 responded. This resulted in an initial list of 13 items. In the original list of 13 items "reputation" and "subject knowledge/publications" were separate elements. However, because of the direct relationship between "subject knowledge/publications" and "reputation" it was deemed prudent to treat them as a single element. Three other elements that conveyed the same sense were "can take a stand", "provide support" and "strong in character". These were taken together and replaced by a single element namely "can take a stand". The selection problem was then formulated using the 10 elements that serve as the criteria for selection. This discussion is presented in the next section.

In the demonstration phase of the study, two groups of five students were randomly selected for a questionnaire survey. One group consisted of only junior students - those who had not yet selected their supervisor - and the other group consisted of five senior students who had already 
worked with their supervisor for at least two years. All the students agreed to participate in the study that required rating the pair wise comparison of the ten elements identified earlier. As the senior students already had supervisors they were asked to rate the pairs on the basis of what they think one should give importance to, while the junior students were asked to rate the pairs based on what they feel is important to them in selecting a thesis supervisor. The AHP formulation for both these groups was then solved and their differences noted. This discussion on findings is presented in section on results.

\section{Supervisor Selection Criteria}

Most often supervisor selection happens based on input from senior doctoral students and one's own understanding of various strengths of the faculty members. The academy of management's doctoral students' liaison committee mentions three key elements to be considered when selecting a dissertation committee: expertise and interest in the topic pursued by the student, contacts with academic and other organizations where one wishes to end up working post dissertation, and good interrelationship between committee members (http://www.aom.pace.edu/students/faqanswers.htm). At a broad level, these elements do cover a majority of the concerns in supervisor selection and most doctoral students do consider them while selecting a thesis supervisor, however a detailed set that students consciously use in selecting a supervisor is rarely documented. To obtain comprehensive selection criteria, the doctoral students at the authors' institute were asked to list all issues they would consider or recommend one should consider before selecting a thesis supervisor. Table 1 presents the final set of ten key elements after suitably rewording some of the elements and dropping some that conveyed the same meaning.

Table 1: Key elements considered in supervisor selection

\begin{tabular}{|c|c|}
\hline Element & Description \\
\hline Freedom to work (FW) & $\begin{array}{l}\text { The professor is open to ideas and is flexible about adopting alter- } \\
\text { ative approaches }\end{array}$ \\
\hline Time conscious (TC) & $\begin{array}{l}\text { The professor is conscious about time taken for completion and is } \\
\text { generally willing to work towards it }\end{array}$ \\
\hline Job prospect (JP) & $\begin{array}{l}\text { The professors' ability to help the candidate in obtaining a suitable } \\
\text { job after completion of dissertation }\end{array}$ \\
\hline $\begin{array}{l}\text { Convergence of interest } \\
(\mathrm{CI})\end{array}$ & The matching of interest of the student and the professor \\
\hline $\begin{array}{l}\text { Reputation/Subject } \\
\text { knowledge/Publications } \\
\text { (RP) }\end{array}$ & The reputation of the professor in his or her field. \\
\hline $\begin{array}{l}\text { Personal relationship with } \\
\text { the professor (PR) }\end{array}$ & Cordial and understanding relationship with the professor \\
\hline Social networks (SN) & $\begin{array}{l}\text { The professors' social network and relationship with other professors } \\
\text { in the institute and outside }\end{array}$ \\
\hline Can take a stand $(\mathrm{CS})$ & $\begin{array}{l}\text { The extent to which the professor will support the student in conten- } \\
\text { tious situations, and defend his or her stand once it has been agreed } \\
\text { upon previously }\end{array}$ \\
\hline $\begin{array}{l}\text { Number of thesis guided } \\
\text { (TG) }\end{array}$ & Number of thesis guided by the professor, the more the better \\
\hline $\begin{array}{l}\text { Commitment and in- } \\
\text { volvement (IN) }\end{array}$ & Professors' enthusiasm in guiding the thesis, emotional investment \\
\hline
\end{tabular}


Ideally a research student would like all the elements to be present in a high degree in a potential supervisor but is unlikely to find a supervisor who is better on each attribute than all other potential supervisors. Therefore a doctoral candidate needs to make choices depending on what is available and what are her own priority ratings of the attributes she seeks in the supervisor. This brings us to the second part of the paper and that is to identify a technique so that the relative importance of the elements can be worked out for any candidate. Thus we need to be able to assign importance weights in an objective manner to the ten elements in Table 1 . The technique that is proposed here is the analytical hierarchy process, which is described briefly in the next section.

\section{Formulating the Supervisor Selection Problem}

Saaty (1980) developed the Analytic Hierarchy Process (AHP) to enable decision making in situations characterized by multiple attributes and alternatives. AHP allows selection and priority ordering of alternatives based on multiple criteria. It is a decision tool that structures a complex decision problem in a hierarchical fashion, allows comparison of tangible and intangible factors, and sets priorities among alternative course of action (Foreman \& Gass, 2001).

There are four major steps in applying the AHP technique:

1. Develop a hierarchy of factors impacting the final decision. This is known as the AHP decision model. In this case these are the ten elements (Table 1) that make up the first level of the hierarchy. The second level is the candidate alternatives, i.e. the set of potential supervisors.

2. Elicit pair wise comparisons between the factors using inputs from decision makers. Pair wise comparison of the elements will allow the derivation of priority/significance weights for the elements. While comparing two elements we follow the simple rule as recommended by Saaty (1980), though more complicated methods using fuzzy triangular numbers are often used to impute values to linguistic variables. The valued assigned to a comparison can range from $1 / 9$ to 9 , where $1 / 9$ would imply that the one element is extremely less important than the other and 9 implies that the element is extremely more important than the other (Saaty, 1980). A case of equal importance is indicated by the value 1. Furthermore the importance of one element with respect to another is the reciprocal of the value assigned to the importance of the second compared to the first. Once a matrix of paired comparisons is obtained the priority weight vector is the Eigen vector of the matrix corresponding to the largest Eigen value. Thus while comparing two elements $\mathrm{X}$ and $\mathrm{Y}$ we assign the values in the following manner.
a. 1 if $\mathrm{X}$ and $\mathrm{Y}$ are equally important
b. 3 if $\mathrm{X}$ is weakly more important than $\mathrm{Y}$
c. 5 if $\mathrm{X}$ is strongly more important than $\mathrm{Y}$
d. 7 if $\mathrm{X}$ is very strongly more important than $\mathrm{Y}$
e. 9 if $\mathrm{X}$ is absolutely more important that $\mathrm{Y}$
f. Reciprocal values are used when $X$ and $Y$ are interchanged.

3. Evaluate relative importance weights at each level of the hierarchy. Here there are only two levels: the criteria elements and the set of potential supervisors.

4. Combine relative importance weights to obtain an overall ranking of the candidate alternatives. In this case the alternatives are the potential supervisors from which the student selects one by using a synthesis process that compares alternatives in light of the relative weights of the criteria elements. 
Figure 1 presents the decision problem as formulated under AHP.

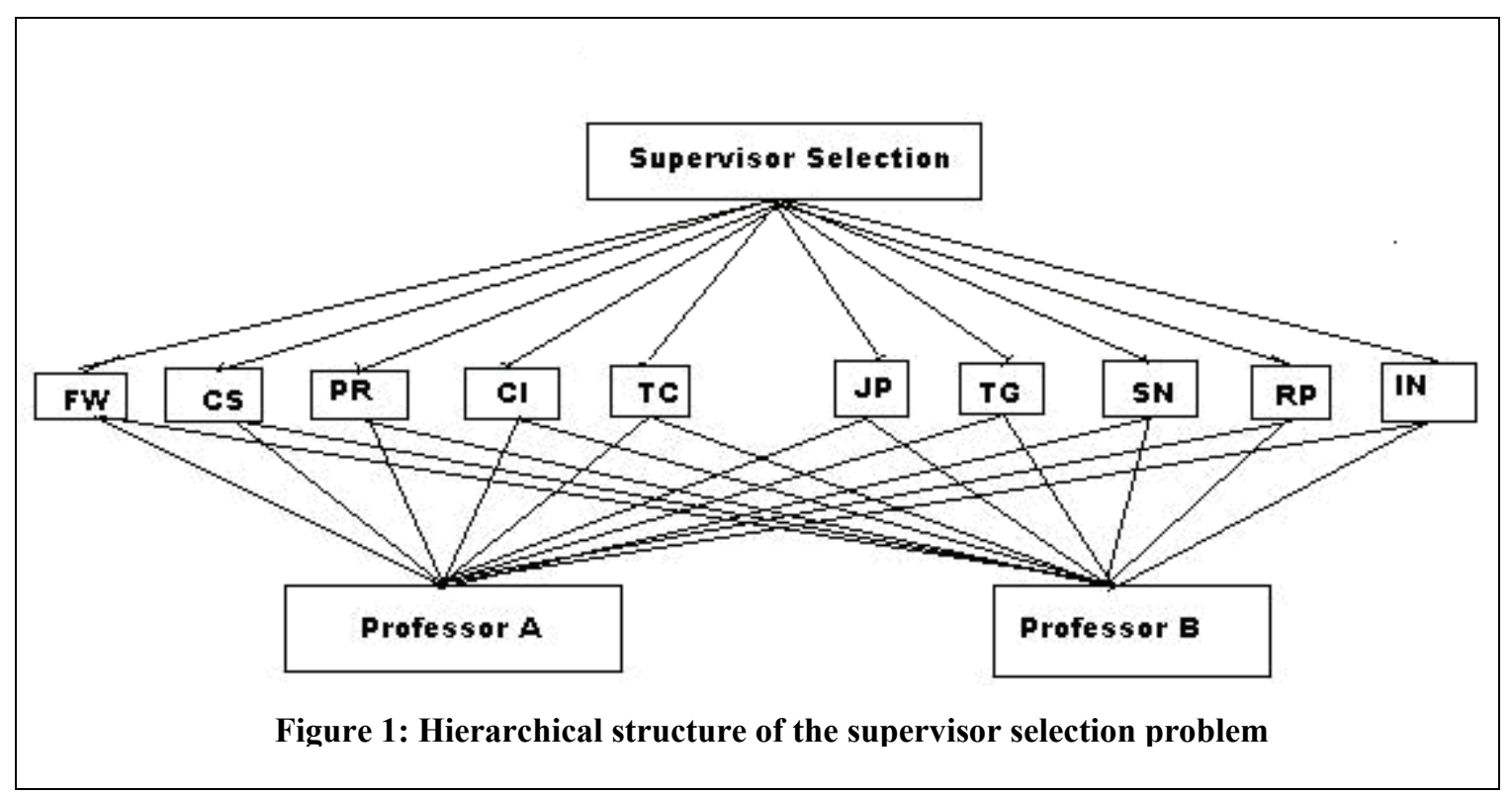

The top level of the hierarchy represents the objective of the decision problem:; in this case, selection of the supervisor is the decision problem being addressed. The set of choices from which a selection has to be made is the last level of the hierarchy. In this case, for the sake of illustration, the student is considering only two faculty members as potential supervisors. This level can have as many alternatives as one wishes without the need to modify the process of obtaining the preference weights. The various criteria that need to be satisfied and any categorization of such criteria make up the middle level of the hierarchy. The problem formulated above is that of selecting a supervisor from the two alternatives, viz Professor A and Professor B. The decision will be based on the relative importance of the elements for the student and the degree of fulfillment of the elements by each of the professors. The professor with highest total rating, which is obtained through a synthesis process, is the one to be selected.

\section{Results}

A pair wise comparison matrix was generated for each group by taking the geometric mean of pair wise ratings by individual members of the group. Table 2 presents the matrix for senior students and Table 3 presents the elements of the matrix pertaining to the junior students. 


\begin{tabular}{|l|r|r|r|r|r|r|r|r|r|r|r|}
\hline \multicolumn{10}{|c|}{ Table 2: Preference weight matrix of the senior students } \\
\hline & FW & TC & JP & CI & RP & PR & SN & CS & TG & IN \\
\hline FW & 1.00 & 0.28 & 0.32 & 0.19 & 0.20 & 0.47 & 0.57 & 0.20 & 1.07 & 0.30 \\
\hline TC & 3.55 & 1.00 & 2.29 & 3.16 & 0.82 & 0.52 & 0.58 & 0.27 & 4.04 & 0.34 \\
\hline JP & 3.16 & 0.44 & 1.00 & 0.62 & 1.03 & 1.07 & 0.86 & 0.48 & 2.81 & 0.35 \\
\hline CI & 5.16 & 0.32 & 1.62 & 1.00 & 1.05 & 0.35 & 0.45 & 0.22 & 2.61 & 0.20 \\
\hline RP & 4.90 & 1.22 & 0.97 & 0.95 & 1.00 & 1.22 & 1.40 & 0.29 & 4.48 & 0.28 \\
\hline PR & 2.14 & 1.93 & 0.93 & 2.89 & 0.82 & 1.00 & 0.91 & 0.47 & 2.61 & 0.41 \\
\hline SN & 1.75 & 1.72 & 1.16 & 2.24 & 0.71 & 1.10 & 1.00 & 0.36 & 4.04 & 0.82 \\
\hline CS & 4.90 & 3.66 & 2.09 & 4.55 & 3.42 & 2.13 & 2.79 & 1.00 & 4.55 & 2.89 \\
\hline TG & 0.93 & 0.25 & 0.36 & 0.38 & 0.22 & 0.38 & 0.25 & 0.22 & 1.00 & 0.20 \\
\hline IN & 3.38 & 2.95 & 2.89 & 4.96 & 3.59 & 2.41 & 1.22 & 0.35 & 4.96 & 1.00 \\
\hline
\end{tabular}

\begin{tabular}{|l|r|r|r|r|r|r|r|r|r|r|}
\hline \multicolumn{10}{|c|}{ Table 3: Preference weight matrix of the junior students } \\
\hline & FW & TC & JP & CI & RP & PR & SN & CS & TG & IN \\
\hline FW & 1.00 & 0.84 & 0.98 & 0.49 & 0.75 & 0.72 & 1.48 & 0.32 & 3.21 & 0.38 \\
\hline TC & 1.18 & 1.00 & 2.54 & 0.95 & 0.49 & 1.05 & 1.93 & 0.21 & 3.00 & 0.20 \\
\hline JP & 1.02 & 0.39 & 1.00 & 1.11 & 0.80 & 1.09 & 1.38 & 0.19 & 2.63 & 0.67 \\
\hline CI & 2.04 & 1.05 & 0.90 & 1.00 & 0.47 & 1.63 & 0.86 & 0.36 & 2.26 & 0.21 \\
\hline RP & 1.33 & 2.04 & 1.25 & 2.14 & 1.00 & 2.54 & 2.17 & 0.39 & 3.16 & 0.30 \\
\hline PR & 1.38 & 0.95 & 0.92 & 0.61 & 0.39 & 1.00 & 2.54 & 0.39 & 1.90 & 0.19 \\
\hline SN & 0.68 & 0.52 & 0.72 & 1.16 & 0.46 & 0.39 & 1.00 & 0.22 & 1.48 & 0.18 \\
\hline CS & 3.16 & 4.83 & 5.16 & 2.81 & 2.54 & 2.54 & 4.51 & 1.00 & 5.52 & 0.54 \\
\hline TG & 0.31 & 0.33 & 0.38 & 0.44 & 0.32 & 0.53 & 0.68 & 0.18 & 1.00 & 0.16 \\
\hline IN & 2.63 & 4.90 & 1.50 & 4.66 & 3.33 & 5.16 & 5.52 & 1.84 & 6.11 & 1.00 \\
\hline
\end{tabular}

After obtaining the Eigen vector for the largest Eigen value (as per the AHP process) of each of these, the priority weights of the elements for each group were obtained as shown in Table 4.

\begin{tabular}{|c|c|c|c|c|}
\hline \multirow[t]{2}{*}{ Items } & \multicolumn{2}{|c|}{ Junior Students } & \multicolumn{2}{|c|}{ Senior Students } \\
\hline & $\begin{array}{r}\text { Importance } \\
\text { Weights }\end{array}$ & Rank & $\begin{array}{r}\text { Importance } \\
\text { Weights }\end{array}$ & Rank \\
\hline Commitment and Involvement (IN) & 0.256023 & 1 & 0.181471 & 2 \\
\hline Can take a stand (CS) & 0.218105 & 2 & 0.24168 & 1 \\
\hline $\begin{array}{l}\text { Reputation/Subject knowl- } \\
\text { edge/Publications (RP) }\end{array}$ & 0.106535 & 3 & 0.09353 & 5 \\
\hline Time conscious (TC) & 0.073429 & 4 & 0.090187 & 6 \\
\hline Convergence of interest (CI) & 0.069824 & 5 & 0.061271 & 8 \\
\hline Job prospect (JP) & 0.06855 & 6 & 0.074942 & 7 \\
\hline Freedom to work (FW) & 0.06611 & 7 & 0.031313 & 9 \\
\hline $\begin{array}{l}\text { Personal relationship with the pro- } \\
\text { fessor (PR) }\end{array}$ & 0.06502 & 8 & 0.095547 & 4 \\
\hline Social networks (SN) & 0.045733 & 9 & 0.100905 & 3 \\
\hline Number of thesis guided (TG) & 0.030672 & 10 & 0.029153 & 10 \\
\hline
\end{tabular}


Two objectives are served by the foregoing analysis. First, a general picture emerges regarding importance given to various elements in selecting a supervisor. Secondly, the analysis brings out the differing priorities of senior/experienced students and students who are about to embark on a research project. While commitment and involvement and can take a stand were the two elements with highest importance for both the groups of students, senior students valued the supervisors' ability to take a stand more than her commitment and involvement in the research work. The junior students however, felt commitment and involvement as the most significant attribute they would look for in a supervisor. One explanation for this could be that students with no research experience are more dependent on their supervisor and while those well into their research projects are more confident of their own ability. Similarly significant differences between importance given to social networks of the supervisor and personal relationship with the professor are noticed between the two groups. To test whether a statistically significant correlation exists between priorities of these two groups, Spearman Rank Order correlation coefficient was computed and found to be 0.539 . At $5 \%$ level of significance for a list of size 10 , the significant value is $0.55(>0.539)$ which indicates that the ranks allotted by the two groups are not significantly correlated. In order words priorities of the attributes sought for in a supervisor are significantly different among the two groups of research students. The statistical difference in rating the elements between the two groups brings out the need for mentoring of fresh research candidates by their more experienced seniors. While mentoring happens informally, a formalized method of grooming research students especially by the seniors can help reduce some of the research related problems engendered from not selecting the best fit supervisor.

Once the importance weights are determined for the attributes, the various alternatives, i.e. the potential supervisors, can be ranked using a synthesis process as illustrated here.

This example assumes that the student is considering two professors from which she will select one as a supervisor. The limitation of two in the example is only for brevity; in practice the same method applies to any number of alternatives. Let us call these alternatives A and B. A value to record the pair wise comparison of $\mathrm{A}$ and $\mathrm{B}$ is given as per the method discussed in the section on Formulating the Supervisor Selection Problem with respect to each of the criteria elements.

Thus for element 5, i.e. Convergence of interest (CI), the students notes down a score that compares $\mathrm{A}$ and $\mathrm{B}$ on the $\mathrm{CI}$ aspect. For example if a students perceives $\mathrm{B}$ to be little better than $\mathrm{A}$ with respect to $\mathrm{CI}$, the score allotted is 5 . The following matrix is generated for the $\mathrm{CI}$ criteria element

\begin{tabular}{|l|l|l|}
\hline & A & B \\
\hline A & 1 & 5 \\
\hline B & $1 / 5$ & 1 \\
\hline
\end{tabular}

The corresponding weights are $\mathrm{A}-0.125$ and $\mathrm{B}-0.875$

The same process is repeated for the remaining 9 attributes to obtain weights for A and B with respect to each of them. The following table is then constructed using the relative weights of the ten elements, and the weights of A and with respect to each of the ten elements. The relative weights for the ten elements are taken from junior students score as given in Table 3 rounded to 3 decimal places. 


\begin{tabular}{|l|r|r|r|}
\hline \multicolumn{3}{|c|}{ Table 5: Final Selection - Illustration } \\
\hline Item & $\begin{array}{r}\text { Importance } \\
\text { weight }\end{array}$ & Professor A & Professor B \\
\hline Commitment and Involvement (IN) & 0.256023 & 0.25 & 0.75 \\
\hline Can take a stand (CS) & 0.218105 & 0.25 & 0.75 \\
\hline $\begin{array}{l}\text { Reputation/Subject knowl- } \\
\text { edge/Publications (RP) }\end{array}$ & 0.106535 & 0.5 & 0.25 \\
\hline Time conscious (TC) & 0.073429 & 0.75 & 0.875 \\
\hline Convergence of interest (CI) & 0.069824 & 0.125 & 0.1 \\
\hline Job prospect (JP) & 0.06855 & 0.9 & 0.5 \\
\hline Freedom to work (FW) & 0.06611 & 0.5 & 0.5 \\
\hline $\begin{array}{l}\text { Personal relationship with the profes- } \\
\text { sor (PR) }\end{array}$ & 0.06502 & 0.5 & 0.5 \\
\hline Social networks (SN) & & 0.045733 & 0.5 \\
\hline Number of thesis guided (TG) & & & 0.5 \\
\hline
\end{tabular}

Total score for $\mathrm{A}=$ sum product of columns 2 and 3 of table $4=0.4238$

Total score for $\mathrm{B}=$ sum product of rows 2 and 4 of table $4=0.5762$

This implies that B should be selected as the supervisor

\section{Limitations}

One of the assumptions implicit in employing this technique is that the student making the choices and paired comparison is mature enough to know the correct priorities. The study also assumes that the student is able to compare objectively two or more candidate supervisors on each of the attributes. In many cases it may so happen that the student has never interacted with a potential supervisor; hence, it becomes impossible to make objective comparison with other candidate supervisors on many of the attributes. Thus a great deal of information from discussion with seniors and other peers is required before such a comparison can be done. This implies a significant responsibility on the candidate to able to gather and process information from different sources. Furthermore, the candidate herself has to be mature enough to have the right expectations from a doctoral research project. For example, a doctoral student who is not a good candidate can still be unhappy with his supervisor in spite of selecting the supervisor with the best fit, mainly because of carrying wrong expectations into the project.

Another important limitation of the study is that it is not verifiable as of now whether supervisor selection done in this way actually leads to better dissertations in terms of time to complete the research, quality of the research, etc. While this creates an opportunity for further research, it also implies that in absence of such evaluative information about this method, there is perhaps little motivation to adopt this approach for supervisor selection. However, the method can be very useful to cross check one's tentative selection or shortlist to a few candidate supervisors from a large set of alternatives. Another situation where this proposed technique is also not applicable is when there are no alternatives available for choosing a supervisor. Such situations can arise when the student is very strongly focused on a particular area of research or the university does not have enough qualified faculty relative to the number of students. Also it must be remembered that supervisor student fit is one of the necessary conditions for good research but not the only one; 
hence, to that extent using this method of selection of supervisor does not imply that the outcome will necessarily be a successful thesis.

\section{Conclusion}

Selecting a research supervisor is an extremely significant initial step in one's journey into the research world. It is therefore important that the decision be made in as informed a manner as possible. In this paper a decision making model based on the AHP technique has been illustrated for the selection of the most suitable professor for the role of thesis supervisor. The AHP techniques illustrated here adds value to human judgment by introducing objectivity and quantification of priorities, allowing students to make a more informed choice of supervisor. It is hoped that the doctoral students can use this approach to validate their own tentative choice and be more confident about the decisions they have made or will make with regard to selecting their thesis supervisor.

\section{References}

Acker, S., Hill, T., \& Black, E. (1994). Thesis Supervision in the social sciences: Managed or Negotiated? Higher Education, 28, 483-498.

Armstrong, S. J., Allison, C. W., \& Hayes, J. (2004). The effects of cognitive style on research supervision: A study of student-supervisor dyads in management education. Academy of Management Learning and Education, 3.

Burnett, P. (1999). The supervision of doctoral dissertation using a collaborative cohort model. Counselor Education and Supervision, 39(1), 46-52.

Cornwall, M. G., Schmithals, F., \& Jaques, D. (Eds.). (1977). What is project orientation? An overview. In Proceedings of the Seminar on Project Orientation in Higher Education, 1-16. University of Bremen, March 1976, University of London, Institute of Education.

Dillon, M. J., \& Malott, R. W. (1981). Supervising masters thesis and doctoral dissertations. Teaching and Psychology, 8(3), 195-202.

Eggleston, J., \& Delamont, S. (1983). Supervision of students for research degrees. Birmingham, AL: BERA.

Forman, E. H., \& Gass, S. I. (2001). The Analytic Hierarchy Process--An exposition. Operations Research, 49(4).

Garcia, M. E., Mallot, R. W., \& Brethower, D. (1988). A system of thesis and dissertation supervision: Helping graduate students succeed, Teaching of Psychology, 7, 89-92.

Harding, A. G. (1973). The objectives and structure of undergraduate projects. British Journal of Educational Technology, 4, 216-232.

Hockey, J. (1991). The social science PhD - A literature review. Studies in Higher Education, 16(3), 319332.

Rudd, E. (1985). A new look at post graduate failure. Guildford, England: SRHE and Slough: NFERNelson

Saaty, T. L. (1980). The Analytical Hierarchy Process. New York: McGraw Hill.

Wright, J., \& Lodwick, R. (1989). The process of the PhD: A study of the first year of doctoral study. Research Papers in Education, 4, 22-56.

Young, K., Fogarty, M. P., \& McRea, S. (1987). The management of doctoral studies in the social sciences. London, England: PSI.

Zoia, T. K. (1981). Completing long term undergraduate projects: Some critical variables. Unpublished masters thesis, Western Michigan University, Kalamazoo, MI. 


\section{Biography}

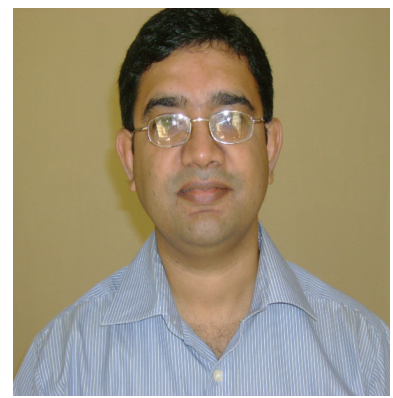

Subhajyoti Ray is an assistant professor at Xavier Institute of Management, India. He currently teaches courses in information systems, and decision sciences. He has completed his doctoral programme from the Indian Institute of Management, Ahmedabad in India, and his research interest is eGovernment in developing countries. 